\title{
Catalytic Sorption of (Chloro)Benzene and Naphthalene in Aqueous Solutions by Granular Activated Carbon Supported Bimetallic Iron and Palladium Nanoparticles
}

\author{
Jurate Virkutyte, ${ }^{1}$ Souhail R. Al-Abed, ${ }^{2}$ Edwin F. Barth, ${ }^{2}$ Danny Reible, ${ }^{3}$ \\ Patrick Dunlap, ${ }^{3}$ and Sandip Chattopadhyay ${ }^{4}$ \\ ${ }^{1}$ Pegasus Technical Services, Inc., 46 E. Hollister Street, Cincinnati, OH 45219, USA \\ ${ }^{2}$ National Risk Management Research Laboratory, U.S. Environmental Protection Agency, 26 West M. L. K. Drive, Cincinnati, \\ OH 45268, USA \\ ${ }^{3}$ Civil, Architectural, and Environmental Engineering Department, University of Texas, Austin, TX 78713, USA \\ ${ }^{4}$ Tetra Tech, Inc., 250 West Court Street, Suite 200W, Cincinnati, OH 45202, USA
}

Correspondence should be addressed to Souhail R. Al-Abed; al-abed.souhail@epa.gov

Received 21 March 2013; Accepted 11 April 2013

Academic Editors: J. He, D. K. Sarker, and D. Tsoukalas

Copyright (C) 2013 Jurate Virkutyte et al. This is an open access article distributed under the Creative Commons Attribution License, which permits unrestricted use, distribution, and reproduction in any medium, provided the original work is properly cited.

\begin{abstract}
Adsorption of benzene, chlorobenzene, and naphthalene on commercially available granular activated carbon (GAC) and bimetallic nanoparticle $(\mathrm{Fe} / \mathrm{Pd})$ loaded GAC was investigated for the potential use in active capping of contaminated sediments. Freundlich and Langmuir linearizations were both applied to this data, and it was found that the Freundlich model most closely fits the experimental data. Based on Freundlich parameters, the effective partitioning coefficients $\left(\mathrm{L} \mathrm{kg}^{-1}\right)$ taking into account $K_{F}$ and $n$ were calculated to be $2.97 \times 10^{6}$ and $8.25 \times 10^{5}$ for benzene and chlorobenzene, respectively, on GAC. In addition, effective partitioning coefficients $\left(\mathrm{L} \mathrm{kg}^{-1}\right)$ were 650,5640 , and $1.91 \times 10^{5}$ for benzene, chlorobenzene, and naphthalene, respectively, on $\mathrm{Fe} / \mathrm{Pd} / \mathrm{GAC}$. Values of $\log K_{F}\left((\mu \mathrm{g} / \mathrm{kg}) /(\mu \mathrm{g} / \mathrm{L})^{n}\right)$ were 6.11, 7.11, and 7.54 for benzene, chlorobenzene, and naphthalene, respectively, for GAC and 4.53, 5.47, and 5.22, respectively, for Fe/Pd/GAC.
\end{abstract}

\section{Introduction}

Globally, sediment contamination is an immense problem in terms of environmental health and remediation costs. As countries continue to adopt more stringent environmental policies, more research and know-how is required to improve or even develop new sediment remediation techniques and understand the fate and transport of contaminants in benthic settings. Contaminated sediments represent a common problem due to their tendency to sequester hazardous materials from different sources including point source municipal and industrial discharges, runoff from urban areas, and contaminated groundwater flow. Sediments mainly consist of minerals and carbon; therefore, they can act as good sorbents for various inorganic and organic contaminants, which can remain long after the source of pollution has been removed.
These contaminated solids are at equilibrium with the porewater in the sediments. It is from here that the hazardous materials can be reemitted through diffusion and advection into the overlying body to water. It is important to point out that porewater dissolved contaminants are bioavailable and available to partition into benthic organisms, which reside in the sediments. Furthermore, the contaminants can bioaccumulate into organisms from the tissue of these lower organisms, which may lead to an ecological and human health concern.

Management of contaminated sediments is rather challenging because of the difficulty in assessing the best option among a plethora of options, which all have drawbacks and risks. The primary remedial options include environmental dredging, in situ capping, and natural recovery. Unfortunately, because of the complexity of the contaminated 
sediment problem and the variability of site constraints there is no single answer to sediment remediation. Environmental dredging includes the removal of contaminated sediment areas from the site, followed by their ultimate disposal off site. Unfortunately, several drawbacks to dredging approach exist, including contaminant resuspension and exposure to residuals. During the dredging process, the contaminant being removed is inevitably reintroduced into the overlaying water or left exposed at the sediment surface, thereby increasing contaminant exposure to biota and potentially increasing contaminant concentration in surface waters. Exposure of humans to volatile and semivolatile contaminants can occur during sediment dredging, processing, and transportation [1]. In addition, other drawbacks are associated with costs and complexity that are related to dredging, dewatering, transportation, and ultimate destruction or disposal of the sediments causing environmental dredging projects to run over budget [2]. On the other hand, natural attenuation is the actual reduction in contaminant bioavailability over time due to natural processes. Several processes are employed in natural attenuation, though typically the most important is the increasing physical separation between the biologically active layer and the contaminated layers due to sedimentation of clean material [3]. Site and contaminant specific properties are the important factors in the efficacy of using natural attenuation. In situ capping is the placement of clean material over the contaminated sediment to separate it from the biota and overlaying water. In this way capping can be regarded as an artificial enhancement of the separation by sedimentation, which occurs during natural attenuation. The material used in capping is commonly a layer of clean sand greater than 20 inches, potentially topped with an armoring layer of stone [4]. However, if the site conditions are such that contaminant transport through the cap is a concern, then active capping is an option, which can significantly reduce or even eliminate this transport [5].

Active capping may significantly reduce the bioavailability through permeability control, the encouragement of biodegradation, or by enhancing sorption of the contaminant to the cap material. In order to be a viable option for an active capping application, material should be cost effective, have high affinity towards the sorption of the target contaminant, be readily settable or in a form such as a mat convenient placement, and be resistant to erosion.

Activated carbons are usually produced from carbonaceous materials such as coal, peat, or agricultural residue and possess adsorption ability for relatively low-molecular weight organic compounds such as aromatic hydrocarbons [6]. These adsorbents can be manufactured in such a way that a highly fractal material with large surface area and highly microporous structure is obtained, which is similarly roughly structured with each magnification and with pores of any width [7]. According to Haghseresht and colleagues [8], the adsorption capacity for activated carbon in liquid-phase adsorption depends on several factors:

(1) the physical nature of the adsorbent, for example, pore structure, ash content, and functional groups;
(2) the nature of adsorbate, its $\mathrm{p} K_{a}$, functional groups present, polarity, molecular weight, and size;

(3) the solution conditions such as $\mathrm{pH}$, ionic strength, and the adsorbate concentration.

It has been reported that, for example, chlorinated pollutants sorb strongly to the activated carbon particles [6]; unfortunately if used alone, activated carbons cannot dechlorinate the contaminants. Thus, different strategies should be employed to effectively destroy organic contamination. According to Choi and colleagues [9], reactive carbons (e.g., activated carbon loaded with nanomaterials) are able not only to adsorb but also to dechlorinate target organic pollutants.

Palladium-based catalytic adsorption has recently emerged as a promising water treatment strategy due to that supported Pd-based bimetallic catalytic adsorbents and/or catalysts can activate dihydrogen $\left(\mathrm{H}_{2}\right)$ and catalyze reductive transformations of a number of contaminants. In general, Pdbased catalysts and/or catalytic adsorbents are more active, stable, and selective for desired end products and/or less toxic than other metals such as Ir, Rh, $\mathrm{Zn}$, and $\mathrm{Ru}$ [10]. However, to further enhance their effectiveness, a promoter metal is required for reduction of contaminants, which does not generally dissociate $\mathrm{H}_{2}$ but facilitates the reduction by using "spillover" Pd- $\mathrm{H}_{\mathrm{ad}}[11]$. Therefore, to enhance metal dispersion and facilitate handling and phase separation, $\mathrm{Pd}$ and promoter metals are often loaded onto the support materials such as activated carbon, alumina, silica, $\mathrm{TiO}_{2}$, and zeolites among a few [10]. It is important to point out that the support can have a direct effect on reactivity through direct participation in the process or through the modification of the electronic properties of the metal particles [12].

Hydrophobic contaminants like benzene, chlorobenzene, and naphthalene are one of the most common contaminants found in groundwater and soils $[13,14]$. Therefore, strategies should be developed to remove these contaminants from soils, sediments, and water.

The main objective of the study is to investigate an emerging option in contaminated sediment remediationthe enhanced sorption of benzene, chlorobenzene, and naphthalene to the cap material, which has great potential for many contaminated sites where existing options may be inadequate in one or several aspects. Specifically, this work explored the options of using granular activated carbon (GAC) and bimetallic (Fe/Pd) nanoparticle loaded activated carbon $(\mathrm{Fe} / \mathrm{Pd} / \mathrm{GAC})$ to amend the conventional capping to improve its effectiveness in removing benzene, chlorobenzene, and naphthalene. Therefore, both sorbents were compared and discussed in details taking into account sorption capacity and potential destruction of contaminants.

\section{Materials and Methods}

2.1. Chemicals. For this study naphthalene was obtained from Alfa Aesar in solid form at $99.6 \%$ purity. Benzene and chlorobenzene were obtained from Fischer Scientific in pure phase liquid form. Granular activated carbon (GAC, Filtersorb 300 (F-300), a bituminous coal based carbon, Calgon 
Carbon Corporation, Pittsburgh, PA, BET surface area of $1050 \mathrm{~m}^{2} \mathrm{~g}^{-1}$ ) was used as received.

2.2. Analyses. Benzene and Chlorobenzene were analyzed by Gas Chromatography with a Flame Ionization Detector (GC-FID) using a headspace autosampler. Unless specified otherwise, $5 \mathrm{~mL}$ of sample was placed in a $22 \mathrm{~mL}$ headspace sampling vial which was then heated and agitated. An aliquot of the vapor phase was sampled and injected into a 30-meter Restek RTX-624 column. The carrier gas was high purity nitrogen at $10 \mathrm{~mL} /$ minute and the temperature program was run as follow: initial temperature $40^{\circ} \mathrm{C}$, held for 3 minutes, ramped to $140^{\circ} \mathrm{C}$ at $20^{\circ} \mathrm{C} /$ minute, ramped to $220^{\circ} \mathrm{C}$ at $50^{\circ} \mathrm{C} /$ minute, and held for 3 minutes. The Flame Ionization Detector does not uniquely identify contaminants and so retention times are used for the identification. Area of the peaks generated by the flame ionization detector to benzene and chlorobenzene over their elution times showed a linear response against compound concentration.

Naphthalene concentration was determined by EPA method 8310 with Waters High Performance Liquid Chromatography. The carrier liquid used was a $70: 30$ acetonitrile and water solution which was passed through a HC-ODS Sil$\mathrm{X}$ column at $1 \mathrm{~mL} /$ minute and $35^{\circ} \mathrm{C}$. Florescent and Ultraviolet Absorbance detectors were both used in series, the former used to detect low concentration from the sub-ppb range to $50 \mu \mathrm{g} / \mathrm{L}$, while the latter was used to detect concentrations greater than $50 \mathrm{ppb}$. Again, these detectors show positive relation to compound concentration and retention time of the peaks was used for positive identification of compounds.

2.3. Distilled Water Batch Tests. Initially, sorption of the less hydrophobic compounds was investigated in batch tests to establish the relative effectiveness of the sorbents and trends associated with contaminant hydrophobicity.

For these batch tests, sorbents were measured into $65 \mathrm{~mL}$ Pyrex centrifuge tubes. The centrifuge tubes were filled with electrolytic/biocide solution containing $10 \mathrm{mM}$ each of sodium chloride, calcium dichloride, and sodium azide. These were then capped with a Mininert brand Teflon cap leaving no headspace. $250 \mu \mathrm{L}$ was removed from each vial to keep any of the contaminant from escaping bottle during spiking. Then, the exact predetermined volume of solution added was determined gravimetrically due to variability in the precise volumes of the centrifuge tubes and the masses of the sorbents added. Finally, a contaminant standard, which contained benzene, chlorobenzene, and naphthalene in methanol was added to the centrifuge tubes with an airtight syringe through the Mininert cap to give the appropriate initial concentration of each contaminant. The volume of stock added was always less than $0.5 \%$ of the volume of the batch to minimize solvent impacts on the matrix in the samples. Along with the samples containing the preweighed mass of sorbent, a sample without any sorbent was run as a sample blank. The samples and sample blanks were allowed to equilibrate in a tumbling box for 7 days. At the end of 7 days the tubes were centrifuged at $3500 \mathrm{rpm}$ for 15 minutes. Then the supernatant from the samples and the sample blanks was extracted through the Mininert cap with an airtight syringe and transferred directly into the appropriate sample vial for analysis.

A total of six (6) batches were run in triplicates where different sorbents were spiked with the same mass of target contaminant. In addition to the batches, the last data point from the kinetics tests was used to add a data point to the isotherms. In some cases an individual data point did not meet quality criteria and was eliminated from the isotherms. In some cases this meant the mass of sorbents was sufficient to reduce the contaminant concentration to nondetects, requiring exclusion of that batch. Also, in some instances, the mass of sorbent was not sufficient to produce a significant reduction in water concentration compared to no sorbent controls, again requiring exclusion of that batch. This means that sorption to the sorbent being tested was similar to sorption to the wall of the vessel or other losses, leading to a high uncertainty in the results. Batches resulting in less than a $20 \%$ reduction in water concentration after sorption were excluded from the results.

2.4. Calculations. A mass balance was used to calculate the concentration of contaminant sorbed to the sorbent as follows:

$$
Q=\frac{C_{I}-C_{E}}{M / V},
$$

where $Q$ is the contaminant concentration on the sorbent, $C_{I}$ is the initial contaminant concentration in water, $C_{E}$ is contaminant concentration in water at equilibrium, $M$ is the mass of the sorbent in the sample, and $V$ is the volume of water in the batch. The initial water concentration was taken to be the concentration in the blank to account for mass losses of the contaminant. For benzene, chlorobenzene, and naphthalene blanks were run in quadruplicates and then averaged.

\section{Results and Discussion}

The selection of a sorbent does not depend upon sorption effectiveness alone. Low cost, weakly sorbing materials may exhibit a better cost/performance ratio than high cost strongly sorbing materials. In addition, use of any material at large contaminated sediment sites requires materials that are available in large volume and where use at these sites would not appreciably increase demand and, therefore, price of the material. Finally, the material used as a sorbent must be able to be placed at a sediment site without substantial loss or subsequent loss of effectiveness.

The surface of carbon consists of many heteroatoms, such as hydrogen, oxygen, nitrogen, sulfur, and phosphorus that are bonded to the edges of the carbon layers, which govern the surface reactions of carbon [15]. Therefore, according to Wibowo and colleagues [16], surface chemistry of carbons has a significant effect on the uptake of small molecules of organic compounds. In the liquid phase adsorption, the adsorbed organic molecules might not be packed with identical orientation. Also, adsorption may be influenced by various factors including $\mathrm{pH}$, solubility of adsorbate in the solvent, and temperature. 


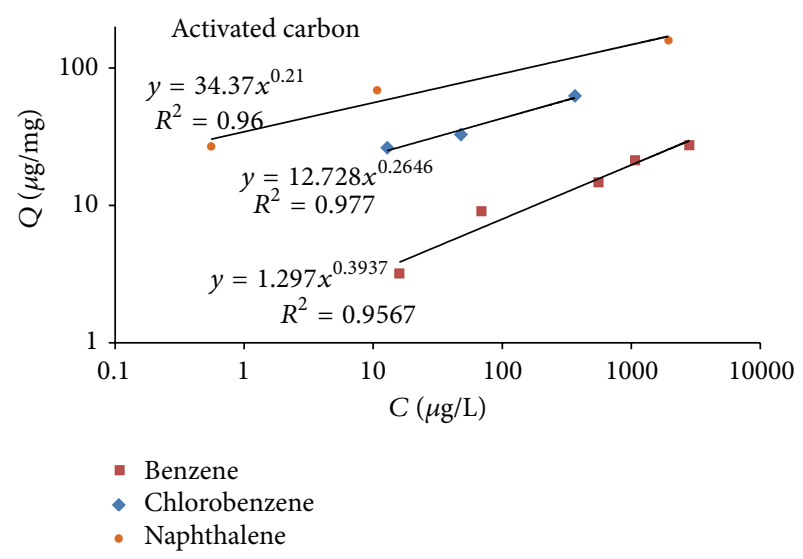

(a)

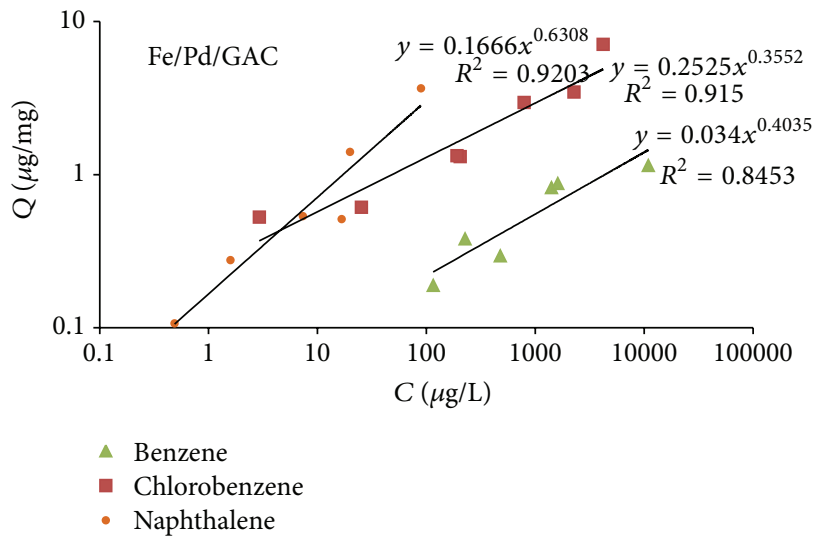

(b)

FIGURE 1: Adsorption isotherms for benzene, chlorobenzene, and naphthalene on (a) GAC and (b) Fe/Pd/GAC.

3.1. Adsorption Controlling Mechanisms. There are two main types of interactions during the aromatic compounds adsorption onto carbons: electrostatic and dispersive [17]. Thus, the functional groups that are linked to adsorptive aromatic ring can activate or deactivate it, delocalizing its charge. According to Kumar and coworkers [18], sorption onto the adsorbent from the aqueous phase involves three main steps: (i) the transport of the adsorbate from the bulk phase to the exterior surface of the adsorbent, (ii) the transport into the adsorbent by either pore diffusion and/or surface diffusion, and (iii) the adsorption on the surface of the adsorbent. It is generally accepted that the adsorption onto the surface is regarded as a fast process; therefore the two remaining steps are responsible for determining the overall rate of adsorption [19]. Furthermore, the rate of uptake is usually limited by adsorbate, adsorbent, and the solution characteristics. Also, particle size of the adsorbent, concentration of the adsorbate, diffusion coefficient of the adsorbate in the bulk phase and the pores of the adsorbent, affinity towards adsorbent, and degree of mixing are important factors as well. The rates of uptake where poor mixing, low concentratation of the adsorbate, and high affinity towards adsorbent as well as small particles are present, are governed by external transport; whereas high concentrations of adsorbate, good mixing, and large particles are present, the rates of uptake are limited by the intraparticle diffusion step [18].

3.2. Adsorption Isotherms. Adsorption isotherms are used to predict the equilibrium loading or being able to determine the interfacial (external carbon surface) equilibrium loading of contaminants during kinetic (i.e., mass transfer rate) experiments [20]. These isotherms or equations usually relate the mass of solute adsorbed per unit of adsorbent to the equilibrium concentration in the liquid phase [21]. Generally, activated carbons have isotherms that obey the Freundlich model [22]. According to the Freundlich isotherm, adsorption at equilibrium can be expressed by

$$
\frac{C_{a}}{M}=K_{F} C_{e}^{1 / n}
$$

where $C_{a}$ is the mass of adsorbate adsorbed, $M$ is the mass of adsorbent, $K_{F}$ is adsorption equilibrium constant, $C_{e}$ is solution concentration at equilibrium after sorption, and $n$ is constant indicative of adsorption intensity. The constants defined in (2) are determined by regressing the log of mass of the adsorbate adsorbed $\left(C_{a} / M\right)$ and the log of the equilibrium concentration $\left(C_{e}\right)$.

Sorption of benzene, chlorobenzene, and naphthalene onto a commercially available GAC was investigated and results are given in Figure 1(a). Residual root-mean-square error (RMSE) and coefficient of determination $\left(R^{2}\right)$ was used to evaluate the goodness of fit. Freundlich and Langmuir linearizations were both applied to the data and it was found that Freundlich model more closely fits the experimental data. This indicates that hydrophobic interactions with the surface of the adsorbent are the actual mechanism of the sorption. The calculated $\log \left(K_{F}\right)$ was $6.11,7.11$, and 7.54; and $n$ was $0.39,0.27$, and 0.21 for benzene, chlorobenzene, and naphthalene, respectively (Table 1 ).

As determined by Zhang et al. [23], micropores and available contact surfaces in the adsorbent should play a dominant role in the adsorption. In order to determine the relations between the adsorbed amounts of benzene, chlorobenzene, and naphthalene and the structural parameters of carbons, volumes occupied by adsorbed contaminants ( $\left.V_{\text {contaminant }}\right)$ were calculated by dividing the $K_{F}$ values with the bulk densities of target contaminants. It is important to point out that the densities of adsorbed contaminants may be lower than their bulk densities, which highly depends on their packing efficiencies in adsorbed state [23]. However, as the information regarding packing efficiency in pores was not available, the bulk densities were used as approximations. Thus, the volumes occupied by adsorbed contaminants on activated carbon were $0.89 \mathrm{mg} \mathrm{L}^{-1}, 0.76 \mathrm{mg} \mathrm{L}^{-1}$, and $0.77 \mathrm{mg} \mathrm{L}^{-1}$ for benzene, chlorobenzene, and naphthalene, respectively. Also, volumes on $\mathrm{Fe} / \mathrm{Pd} / \mathrm{GAC}$ were $0.75 \mathrm{mg} \mathrm{L}^{-1}, 0.66 \mathrm{mg} \mathrm{L}^{-1}$, and $0.63 \mathrm{mg} \mathrm{L}^{-1}$ for benzene, chlorobenzene, and naphthalene, respectively. This indicates that adsorption sites on both sorbents are equally available and bimetallic nanoparticles 
TABLE 1: Adsorption parameters of benzene, chlorobenzene, and naphthalene on GAC and Fe/Pd/GAC.

\begin{tabular}{|c|c|c|c|c|c|c|}
\hline Contaminant & Carbon & $\begin{array}{c}\text { Freundlich } \\
\text { adsorption } \\
\text { coefficient, } \log K_{F} \\
\left((\mu \mathrm{g} / \mathrm{kg}) /(\mu \mathrm{g} / \mathrm{L})^{n}\right)\end{array}$ & $\begin{array}{l}\text { Exponential } \\
\text { term, } n(-)\end{array}$ & $\begin{array}{l}\text { Volume occupied by } \\
\text { adsorbed contaminant, } \\
V_{\text {contaminant }}\left(\mathrm{mL} \mathrm{g}^{-1}\right)\end{array}$ & $\begin{array}{l}\text { Octanol-water } \\
\text { partition } \\
\text { coefficient, } K_{\mathrm{ow}}\end{array}$ & $\begin{array}{c}\text { Effective } \\
\text { partitioning } \\
\text { coefficient, } \\
K_{D}\left(\mathrm{~L} \mathrm{~kg}^{-1}\right)\end{array}$ \\
\hline Benzene & GAC & 6.11 & 0.39 & 0.89 & 2.13 & $2.97 \times 10^{6}$ \\
\hline Chlorobenzene & GAC & 7.11 & 0.27 & 0.76 & 2.84 & $8.25 \times 10^{5}$ \\
\hline Naphthalene & GAC & 7.54 & 0.21 & 0.77 & 3.34 & $*$ \\
\hline Benzene & $\mathrm{Fe} / \mathrm{Pd} / \mathrm{GAC}$ & 4.53 & 0.4 & 0.75 & 2.13 & 650 \\
\hline Chlorobenzene & $\mathrm{Fe} / \mathrm{Pd} / \mathrm{GAC}$ & 5.47 & 0.31 & 0.66 & 2.84 & 5640 \\
\hline Naphthalene & $\mathrm{Fe} / \mathrm{Pd} / \mathrm{GAC}$ & 5.22 & 0.63 & 0.63 & 3.34 & $1.91 \times 10^{5}$ \\
\hline
\end{tabular}

${ }^{*}$ Due to high sorbent concentration, no naphthalene was detected in the equilibrium solution.

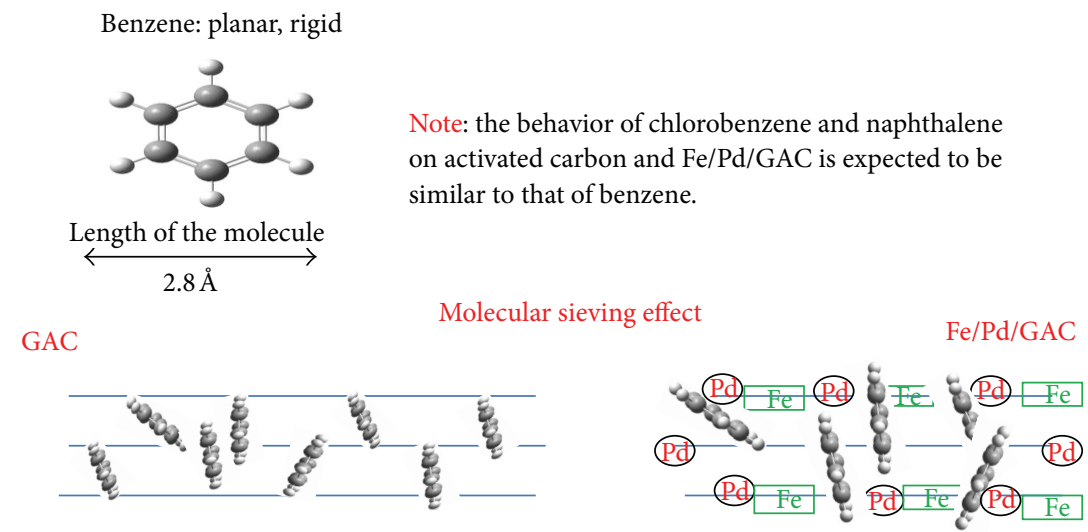

Micropore effect
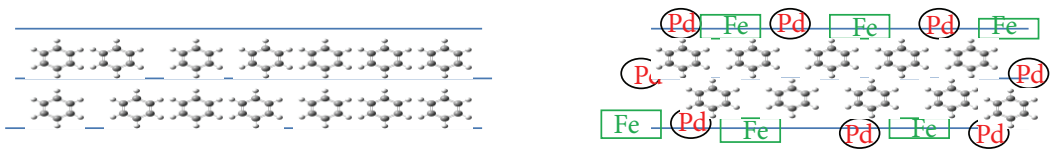

SCHEME 1: Schematic presentation of adsorption sites for target contaminants on GAC and Fe/Pd/GAC (adapted from [23, page 6381]).

(Fe/Pd) did not entirely fill the active sites on activated carbon preventing the contaminants from sorption.

Scheme 1 shows the adsorption sites for contaminant adsorption on GAC and Fe/Pd/GAC. During adsorption process, overlapping potentials of opposite walls in carbons make the adsorption energies much stronger in micropores than those in meso- and macropores [24]. Indeed, the pore sizes of GAC and Fe/Pd/GAC were $150 \AA$ [25] in comparison to $47 \AA$ in $\mathrm{Fe} / \mathrm{Pd} / \mathrm{GAC}$ [9], indicating that micropore effect may in fluence the adsorption if contaminants molecular sizes are larger than the pore sizes of the adsorbents. However, as the size of benzene and chlorobenzene was ca. $2.8 \AA$ and naphthalene ca. $6 \AA$, in the current study, micropore effect was not assumed to be predominant. On the other hand, ca. $20 \%$ of pores in activated carbons are micropores, which may impact the adsorbability of larger molecules like naphthalene in this case.

Molecular sieving effect may also occur because the pore width can be narrower than the molecular size of the contaminant or because the shape of the pores does not allow the contaminant to get into the micropores [23]. As determined by Zhang and colleagues [23], carbons usually have slitshaped pores and the smallest dimension of the adsorbate becomes the determining factor for accessibility to the pores. Thus, the controlling molecular dimensions of target contaminants in the current study were in the order of naphthalene > chlorobenzene $>$ benzene for the slit-shaped carbon sorbents. The adsorption affinities of $\mathrm{Fe} / \mathrm{Pd} / \mathrm{GAC}$ (on mass basis) were smaller than those of GAC (Figure 1), suggesting that molecular sieving effect may have played a role in adsorption of target contaminants due to the presence of Fe/Pd nanoparticles on the surface of GAC.

It is evident from Table 1 that adsorbability of contaminants was in the order naphthalene $>$ chlorobenzene $>$ benzene. Such a difference in adsorbability could be explained in terms of the solubility, $\mathrm{pH}$, chemical structure, presence of colloidal material, and density [18]. The sorption of hydrophobic compounds such as benzene, chlorobenzene, and naphthalene from the aqueous phase increases as the solubility of the compounds decreases (or the octanol-water partition coefficient $K_{\mathrm{ow}}$ increases) [26]. Indeed, the $K_{\mathrm{ow}}$ for benzene, chlorobenzene, and naphthalene were 2.13, 


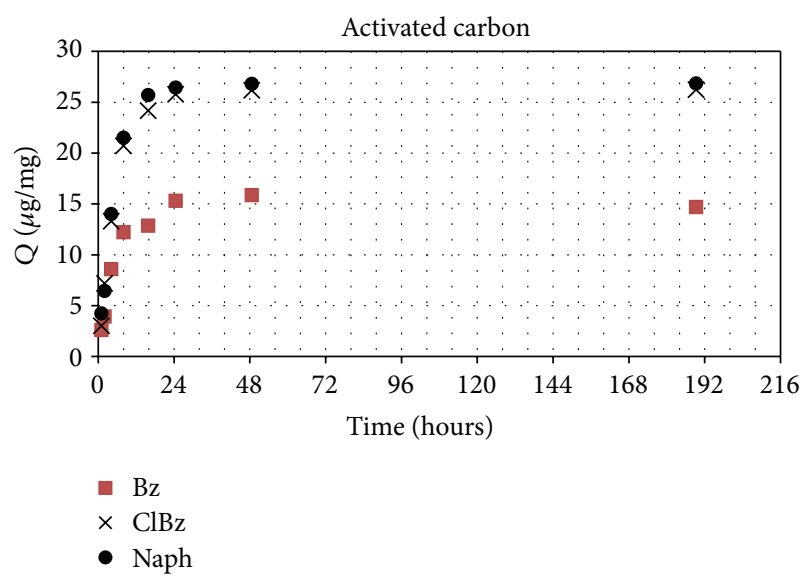

(a)

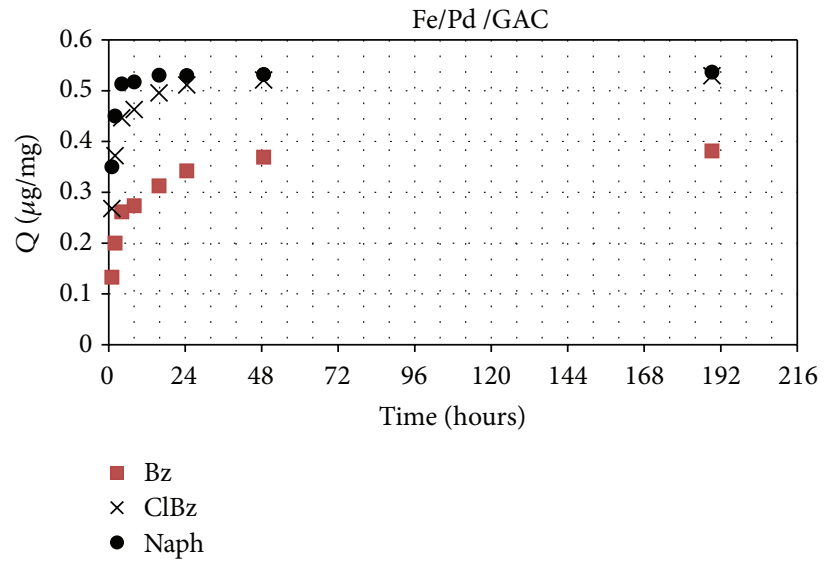

(b)

Figure 2: The rate of benzene, chlorobenzene, and naphthalene uptake on (a) GAC and (b) on Fe/Pd/GAC.

2.84, and 3.34, respectively (Table 1 ) indicating that the sorptive behavior of these contaminants was governed by this hydrophobic characteristics. Sorption of the same contaminants to the novel material Fe/Pd/GAC also indicated the best fit with Freundlich isotherm (Figure 1(b)). In this case $\log \left(K_{F}\right)$ was $4.53,5.47$, and 5.22 ; and $n$ was $0.40,0.31$, and 0.63 for benzene, chlorobenzene, and naphthalene, respectively (Table 1).

As benzene, chlorobenzene, and naphthalene were in the molecular form, dispersive interactions were prevalent, mainly because of the attraction between the $\pi$ orbital on the carbon basal planes and the electronic density in benzene, chlorobenzene, and naphthalene aromatic rings $(\pi-\pi$ interactions) [17]. Also, increased sorption of naphthalene in comparison to benzene and chlorobenzene may also be influenced by the chemical structure. For instance, greater electron density in naphthalene supplies more $\pi$-electrons to interact with the sorbent and subsequently results in larger sorption capacity [27]. Also, differences in sorption capacity between GAC and Fe/Pd/GAC may be related to the physical properties of the sorbents. For example, GAC had a higher surface area than nanosorbent, which may influence the sorption capacity. However, only adsorption of contaminates occurs on the surface of GAC, whereas adsorption and the subsequent degradation of contaminants take place on the surface of Fe/Pd/GAC. As demonstrated by Choi and colleagues [9], following reactions occur simultaneously or in parallel on the surface of the nanosorbent: (i) sequestration of contaminant by $\mathrm{Fe} / \mathrm{Pd} / \mathrm{GAC}$, (ii) nearly simultaneous destruction of adsorbed contaminant by Fe/Pd particles and (iii) the formation of less toxic, and usually biodegradable by-product which is instantly and strongly adsorbed to $\mathrm{Fe} / \mathrm{Pd} / \mathrm{GAC}$. However, further research to identify an exact mechanism of catalytic adsorption of benzene, chlorobenzene, and naphthalene on $\mathrm{Fe} / \mathrm{Pd} / \mathrm{GAC}$ is highly warranted.

3.3. Sorption Kinetics. Generally, sorption process occurs within the boundary layer around the sorbent and proceeds in the liquid filled pores or along the walls of the pores of the sorbent [26]. Owing to their simplicity, batch studies were conducted to determine the reaction kinetics and to compare the effectiveness of two adsorbents, namely, GAC and $\mathrm{Fe} / \mathrm{Pd} / \mathrm{GAC}$. The concentration versus time plots for the adsorption of benzene, chlorobenzene, and naphthalene onto the GAC and Fe/Pd/GAC is shown in Figure 2. It can be seen that the order of the highest extent and rate of adsorption was for naphthalene $>$ chlorobenzene $>$ benzene.

3.4. Partitioning Coefficients. According to Table 1 and Figure 3, $K_{D}$ increased with an increase in hydrophobicity in the case of Fe/Pd/GAC; however it did not follow the same pattern in the presence of GAC. On the other hand, $K_{F}$ values increased with an increase in hydrophobicity. Fe/Pd/GAC was about 2 orders of magnitude lower in $K_{F}$ than GAC. Also, exponential term was significantly higher (0.63) for napthalene in the presence of $\mathrm{Fe} / \mathrm{Pd} / \mathrm{GAC}$, which may be attributed to the molecular sieving effect and the presence of $\mathrm{Fe} / \mathrm{Pd}$ nanoparticles on the surface of GAC, which may influence the sorptive behavior.

3.5. Practical Consideration and Implications. Adsorption of organic contaminants is generally subjected to three effects: (1) micropore, (2) molecular sieving, and (3) hydrophobic effects [23]. According to the results of the current study, adsorption capacities of GAC were higher than those of $\mathrm{Fe} / \mathrm{Pd} / \mathrm{GAC}$. This may be attributed to the higher porosity and a surface area of commercially available activated carbons. Therefore, if only taking into account the adsorption capacity of sorbents, Fe/Pd/GAC was less advantageous than GAC. However, one of the advantages of $\mathrm{Fe} / \mathrm{Pd} / \mathrm{GAC}$ is the simultaneous adsorption and destruction of organic contaminants [9]; therefore further research is absolutely necessary to evaluate the effectiveness of nanoparticle-loaded GACs for greater array of contaminants.

As stated by some of the vendors, for example, Calgon, Donau, General Carbon Corporation, the price for activated carbons is in the range of $\$ 1.5 / \mathrm{lb}$ to $\$ 4.2 / \mathrm{lb}$, which is very comparable to the price of another widely available and 


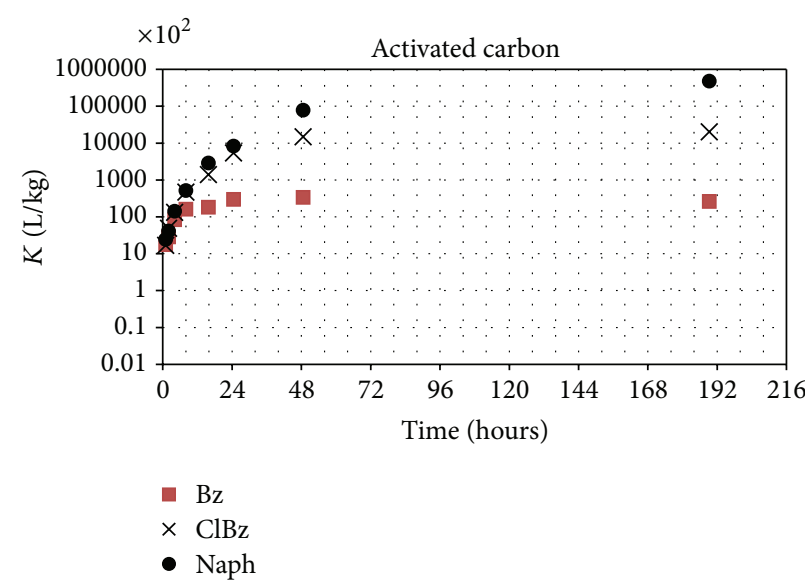

(a)

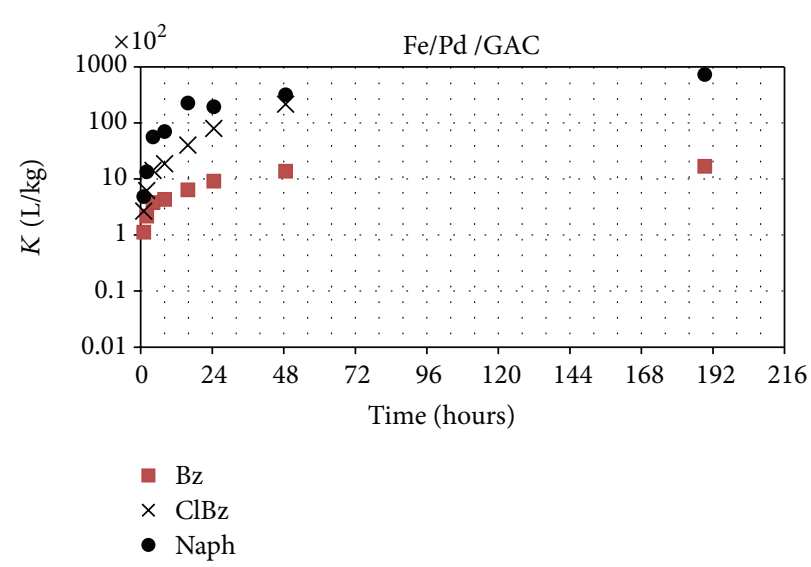

(b)

Figure 3: Effective partitioning coefficients for benzene, chlorobenzene, and naphthalene on (a) GAC and (b) Fe/Pd/GAC.

greatly utilized adsorbent, applicable for in situ uses, clays. There is one drawback associated with the in situ deployment of activated carbons, which is lesser density than sand, which translates into lower settling velocity. This would make the deployment of a mixed granular activated carbon and sand layer difficult, and if it deployed successfully there may be a tendency for the materials to separate over time. However, there are research attempts that develop novel deployment techniques involving the hydraulic placement of these materials [28].

Assuming that the GAC used in the synthesis of $\mathrm{Fe} / \mathrm{Pd} /$ GAC is the same as the aforementioned costs, it is safe to assume that nanosorbent will cost considerably more. The raw materials and increased processing costs alone will likely increase the cost of this material by an order of magnitude if it is commercially implemented. However, if the nanosorbent is able not only to adsorb but also to destroy organic contaminants, the overall costs of the soil or sediments treatment process become very much comparable if not lower in comparison to the use of commercially available GAC.

\section{Conclusions}

(1) Sorption of benzene, chlorobenzene, and naphthalene on commercially available granular activated carbon (GAC) and Fe/Pd/GAC was successfully investigated utilizing kinetic tests and isotherms. The Freundlich model fitted well the experimental data $\left(R^{2}=0.99\right)$.

(2) Based on Freundlich parameters, the effective partitioning coefficients $\left(\mathrm{L} \mathrm{kg}^{-1}\right)$ taking into account $K_{F}$ and $n$ were calculated to be $2.97 \times 10^{6}$ and $8.25 \times 10^{5}$ for benzene and chlorobenzene, respectively, on GAC. Unfortunately, due to high sorbent concentration, no naphthalene was detected in the equilibrium solution. In addition, effective partitioning coefficients $\left(\mathrm{L} \mathrm{kg}^{-1}\right)$ were 650,5640 , and $1.91 \times 10^{5}$ for benzene, chlorobenzene, and naphthalene, respectively, on Fe/Pd/GAC.
(3) Values of $\log K_{F}\left((\mu \mathrm{g} / \mathrm{kg}) /(\mu \mathrm{g} / \mathrm{L})^{n}\right)$ were $6.11,7.11$, and 7.54 for benzene, chlorobenzene, and naphthalene, respectively, for GAC and 4.53, 5.47, and 5.22, respectively, for $\mathrm{Fe} / \mathrm{Pd} / \mathrm{GAC}$.

\section{Acknowledgments}

This research was funded and conducted by the National Risk Management Research Laboratory (NRMRL) of U.S. Environmental Protection Agency, Cincinnati, OH. This paper has not been subjected to internal policy review of the U.S. EPA. Therefore, the research results do not necessarily reflect the views of the agency or its policy. Mention of trade names and commercial products does not constitute endorsement or recommendation for use. This paper has not been subjected to internal policy review of the U.S. EPA.

\section{References}

[1] W. Flynn, "Air quality case histories of an emerging issue for environmental dredging," in Proceedings of the 5th International Conference on Remediation of Contaminated Sediments, Batelle, Jacksonville, Fla, USA, 2009.

[2] T. J. Estes, "Environmental dredging project costs-The Mystery, the Mystique, the Muddle," in Proceedings of the 4th International Conference on Remediation of Contaminated Sediments, Batelle, Savannah, Ga, USA, 2007.

[3] U. Förstner and S. E. Apitz, "State of the Art in the USA Sediment Remediation: U.S. focus on capping and monitored natural recovery," in Proceedings of the 4th International Battelle Conference on Remediation of Contaminated Sediments, pp. 351358, Focus.

[4] A. S. Knox and M. H. Paller, "Active caps for remediation of contaminants and resistance to erosion-field evaluation," in Proceedings of the 5th International Conference on Remediation of Contaminated Sediments, Batelle, Jacksonville, Fla, USA, 2009.

[5] D. Reible, D. Lampert, D. Constant, R. D. Mutch Jr., and Y. Zhu, "Active capping demonstration in the Anacostia River, 
Washington, DC, USA," Remediation Journal, vol. 17, no. 1, pp. 39-53, 2006.

[6] A. M. P. Oen, B. Beckingham, U. Ghosh et al., "Sorption of organic compounds to fresh and field-aged activated carbons in soils and sediments," Environmental Science and Technology, vol. 46, no. 2, pp. 810-817, 2012.

[7] A. Dąbrowski, P. Podkościelny, Z. Hubicki, and M. Barczak, "Adsorption of phenolic compounds by activated carbon-a critical review," Chemosphere, vol. 58, no. 8, pp. 1049-1070, 2005.

[8] F. Haghseresht, S. Nouri, J. J. Finnerty, and G. Q. Lu, "Effects of surface chemistry on aromatic compound adsorption from dilute aqueous solutions by activated carbon," Journal of Physical Chemistry B, vol. 106, no. 42, pp. 10935-10943, 2002.

[9] H. Choi, S. Agarwal, and S. R. Al-Abed, "Adsorption and simultaneous dechlorination of PCBs on $\mathrm{GAC} / \mathrm{Fe} / \mathrm{Pd}$ : mechanistic aspects and reactive capping barrier concept," Environmental Science and Technology, vol. 43, no. 2, pp. 488-493, 2009.

[10] B. P. Chaplin, M. Reinhard, W. F. Schneider et al., "Critical review of Pd-based catalytic treatment of priority contaminants in water," Environmental Science and Technology, vol. 46, no. 7, pp. 3655-3670, 2012.

[11] H. L. Tierney, A. E. Baber, J. R. Kitchin, and E. C. H. Sykes, "Hydrogen dissociation and spillover on individual isolated palladium atoms," Physical Review Letters, vol. 103, no. 24, Article ID 246102, 2009.

[12] M. O. Nutt, J. B. Hughes, and M. S. Wong, "Designing Pdon-Au bimetallic nanoparticle catalysts for trichloroethene hydrodechlorination," Environmental Science and Technology, vol. 39, no. 5, pp. 1346-1353, 2005.

[13] M. C. Ncibi, B. Mahjoub, and R. Gourdon, "Effects of aging on the extractability of naphthalene and phenanthrene from Mediterranean soils," Journal of Hazardous Materials, vol. 146, no. 1-2, pp. 378-384, 2007.

[14] N. Chung and M. Alexander, "Effect of concentration on sequestration and bioavailability of two polycyclic aromatic hydrocarbons," Environmental Science and Technology, vol. 33, no. 20, pp. 3605-3608, 1999.

[15] A. Aygün, S. Yenisoy-Karakaş, and I. Duman, "Production of granular activated carbon from fruit stones and nutshells and evaluation of their physical, chemical and adsorption properties," Microporous and Mesoporous Materials, vol. 66, no. 2-3, pp. 189-195, 2003.

[16] N. Wibowo, L. Setyadhi, D. Wibowo, J. Setiawan, and S. Ismadji, "Adsorption of benzene and toluene from aqueous solutions onto activated carbon and its acid and heat treated forms: influence of surface chemistry on adsorption," Journal of Hazardous Materials, vol. 146, no. 1-2, pp. 237-242, 2007.

[17] F. Villacañas, M. F. R. Pereira, J. J. M. Órfão, and J. L. Figueiredo, "Adsorption of simple aromatic compounds on activated carbons," Journal of Colloid and Interface Science, vol. 293, no. 1, pp. 128-136, 2006.

[18] A. Kumar, S. Kumar, and S. Kumar, "Adsorption of resorcinol and catechol on granular activated carbon: equilibrium and kinetics," Carbon, vol. 41, no. 15, pp. 3015-3025, 2003.

[19] W. J. Weber Jr., Physicochemical Processes for Water Quality Control, Wiley-Interscience, New York, NY, USA, 1972.

[20] A. H. Mollah and C. W. Robinson, "Pentachlorophenol adsorption and desorption characteristics of granular activated carbon-I. Isotherms," Water Research, vol. 30, no. 12, pp. 29012906, 1996.
[21] R. G. Zytner, "Sorption of benzene, toluene, ethylbenzene and xylenes to various media," Journal of Hazardous Materials, vol. 38, no. 1, pp. 113-126, 1994.

[22] S. Zhang, T. Shao, H. S. Kose, and T. Karanfil, "Adsorption kinetics of aromatic compounds on carbon nanotubes and activated carbons," Environmental Toxicology and Chemistry, vol. 31, no. 1, pp. 79-85, 2012.

[23] S. Zhang, T. Shao, H. S. Kose, and K. Tanju, "Adsorption of aromatic compounds by carbonaceous adsorbents: a comparative study on granular activated carbon, activated carbon fiber, and carbon nanotubes," Environmental Science and Technology, vol. 44, no. 16, pp. 6377-6383, 2010.

[24] M. M. Dubinin, "Fundamentals of the theory of adsorption in micropores of carbon adsorbents: characteristics of their adsorption properties and microporous structures," Carbon, vol. 27, no. 3, pp. 457-467, 1989.

[25] Q. Lu and G. A. Sorial, "Adsorption of phenolics on activated carbon-impact of pore size and molecular oxygen," Chemosphere, vol. 55, no. 5, pp. 671-679, 2004.

[26] C. Valderrama, X. Gamisans, X. de las Heras, A. Farrán, and J. L. Cortina, "Sorption kinetics of polycyclic aromatic hydrocarbons removal using granular activated carbon: intraparticle diffusion coefficients," Journal of Hazardous Materials, vol. 157, no. 2-3, pp. 386-396, 2008.

[27] K. Wagner and S. Schulz, "Adsorption of phenol, chlorophenols, and dihydroxybenzenes onto unfunctionalized polymeric resins at temperatures from $294.15 \mathrm{~K}$ to $318.15 \mathrm{~K}$," Journal of Chemical and Engineering Data, vol. 46, no. 2, pp.322-330, 2001.

[28] A. Archer, "In situ waterjet placement of powdered activated carbon in contaminated sediments," in Proceedings of the 6th International Conference on Remediation of Contaminated Sediments, Batelle, New Orleans, La, USA, 2011. 

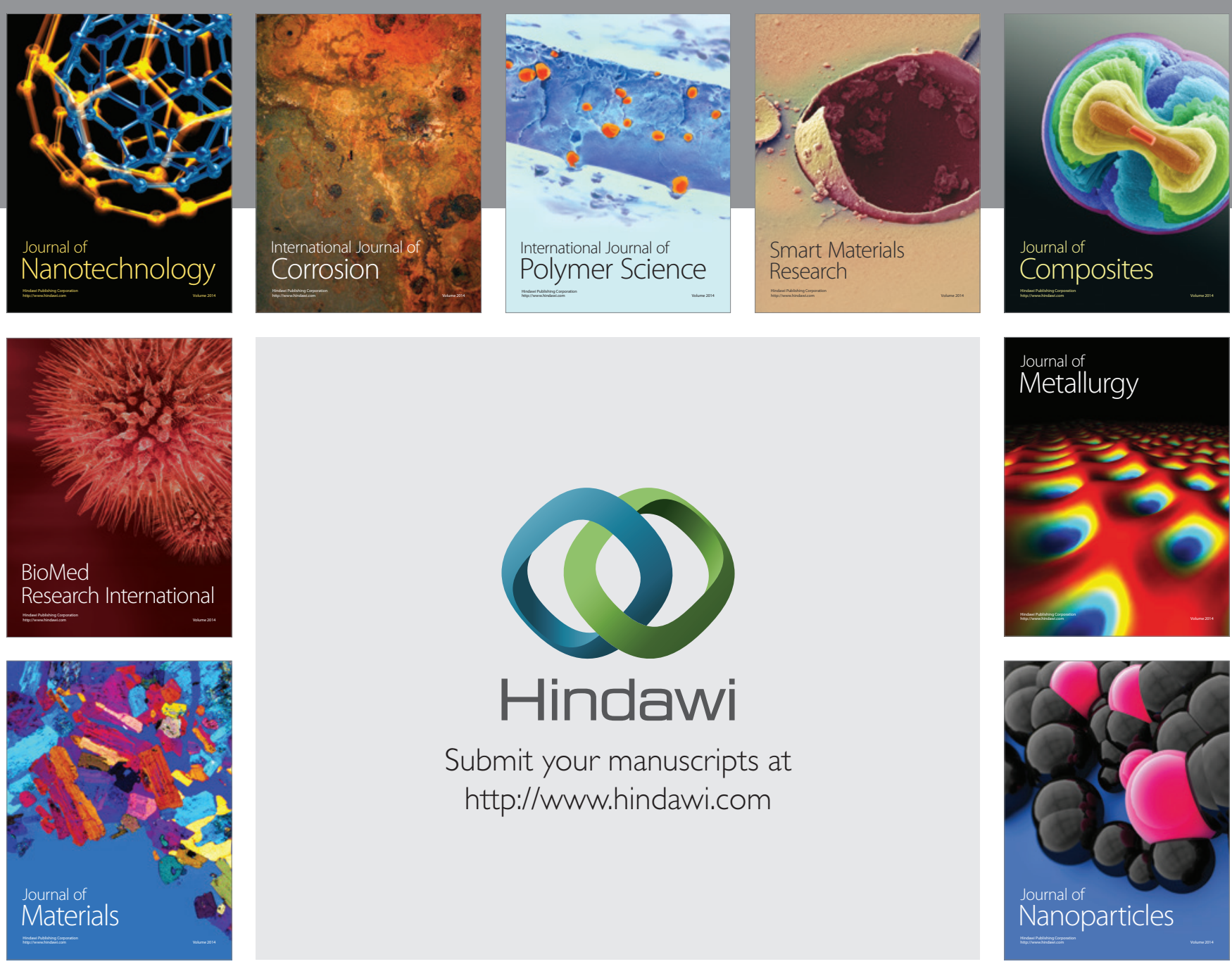

Submit your manuscripts at http://www.hindawi.com
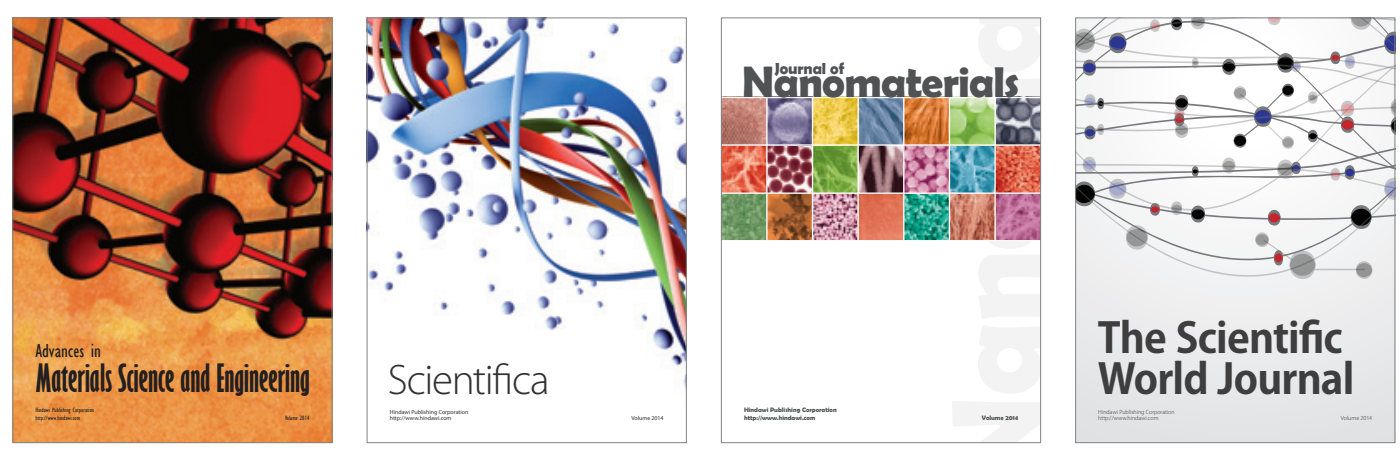

\section{The Scientific World Journal}
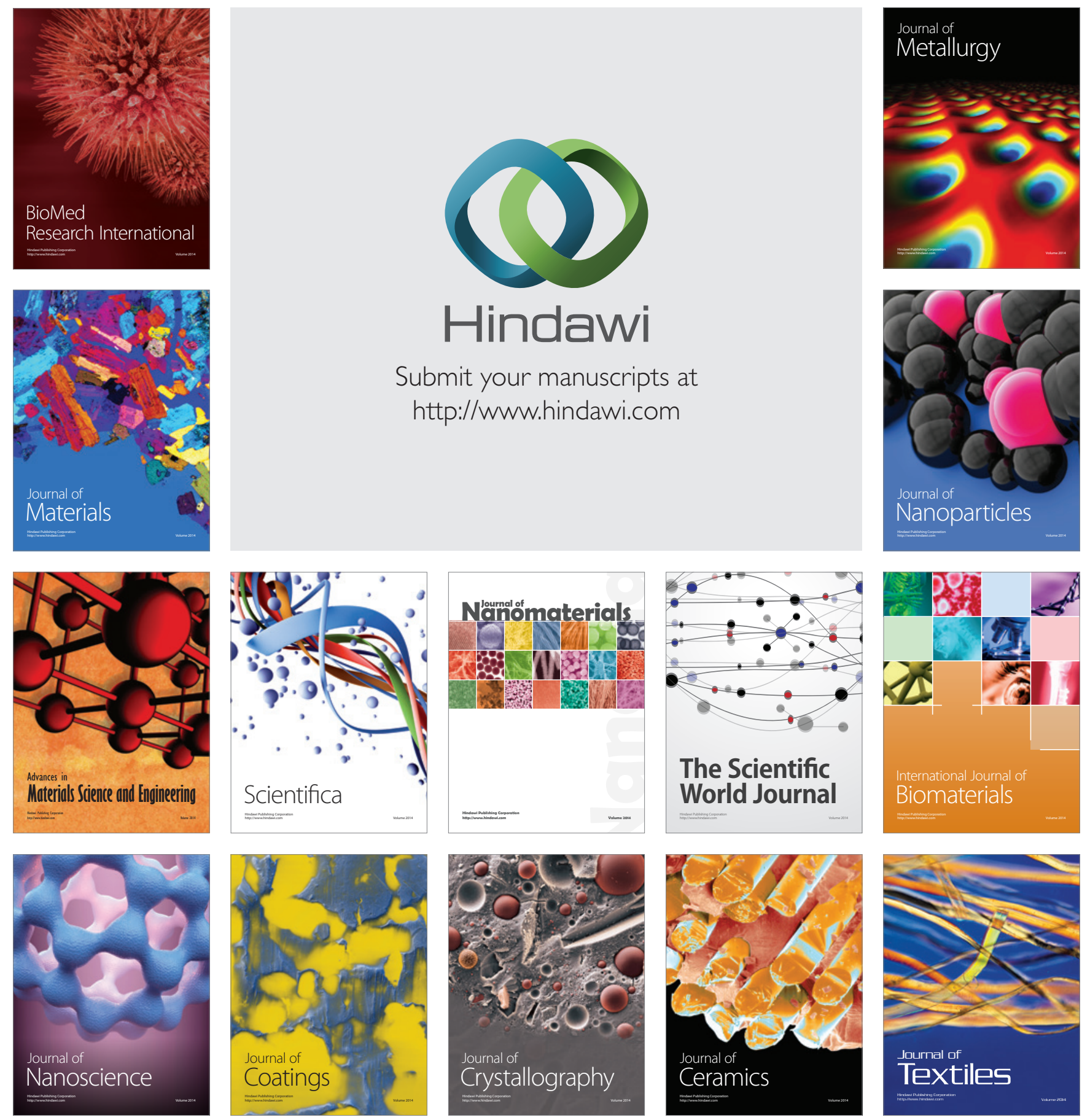